\title{
Contrasting patterns in leaf traits of Mediterranean shrub communities along an elevation
}

4 Giandiego Campetella ${ }^{1}$, Stefano Chelli ${ }^{1 *}$, Camilla Wellstein ${ }^{2}$, Emmanuele Farris $^{3}$, Giacomo Calvia ${ }^{4}$,

$8{ }^{1}$ School of Biosciences and Veterinary Medicine, Plant Diversity and Ecosystems Management

9 Unit, University of Camerino, Via Pontoni 5, I-62032 Camerino, MC, Italy.

$10{ }^{2}$ Faculty of Science and Technology, Free University of Bozen-Bolzano, Piazza Università 5, I-

1139100 Bozen, Italy.

$12{ }^{3}$ Department of Chemistry and Pharmacy, University of Sassari, Via Piandanna 4, I-07100 Sassari, 13 SS, Italy.

$14{ }^{4}$ DISVA, University of Cagliari, Viale Sant'Ignazio da Laconi, 13, I-09123 Cagliari, Italy.

$15{ }^{5}$ Lviv University Botanical Garden, Botanical Garden of Lviv, Ivan Franko str. Cheremshyna, 44

16 Street. Cyril and Methodius, 4, Lviv, 79014 Ukraine.

$17 \quad{ }^{6}$ San Diego State University Research Foundation, 5250 Campanile Drive, San Diego, CA 92182

18 USA.

* Corresponding author: stefano.chelli@unicam.it 
ABSTRACT

37 We assessed the changes in community weighted mean (CWM) and variability of specific leaf area 38 (SLA) and leaf area (LA) of different Mediterranean shrub communities along an elevation gradient 39 in the island of Sardinia (Italy). Furthermore, we explored the relative contribution of species 40 turnover and intraspecific variation to shifts in CWM values along the gradient.

41 Forty sampling units $(5 \times 5 \mathrm{~m})$ were selected in a probabilistic way along a 1,300 $\mathrm{m}$ elevation gradient 42 which crossed four thermotypes (thermometric belts). Leaf traits were measured in each sampling 43 unit. ANOVA and a trend test for monotonic changes in variance were used to assess respectively 44 CWM differences and variability in both the leaf traits across thermotypes. Variance decomposition of CWM values was used to identify the role of inter- and intraspecific variation.

SLA and LA responded differently along the studied gradient in terms of abundance weighted mean values and variability: CWM of SLA showed the lowest values in the driest thermotype, while LA in the more humid one; SLA variability showed a significant increasing trend with increased water availability, while LA variability did not show any pattern. The contribution of intraspecific trait variation was significant for both the leaf traits, but higher for SLA, where negative covariation between inter- and intraspecific variation was detected.

We highlight the importance of simultaneously considering measurements of both leaf traits to understand the functional response of communities in Mediterranean environments. Moreover, neglecting intraspecific variation in leaf traits, even along steep gradients with relevant species compositional changes, can result in the underestimation of the amount of trait variation in response to environmental changes.

Keywords: community weighted mean; interspecific and intraspecific variation; leaf area; plant functional traits; specific leaf area, trait-environment relationship.

Running head: Leaf traits variation in Mediterranean shrublands 
72 INTRODUCTION A large number of studies have identified relationships between traits and environmental conditions (Garnier et al. 2016 and references therein), such as climate and soil properties at different scales and in different regions and systems (e.g. Ackerly 2004; Wright et al. 2004; Ordonez et al. 2009). However, the extent to which such patterns can be generalized beyond the studied scale/region/system is still unknown (Shipley et al. 2016). In particular, despite the Mediterranean biogeographic region being one of the world's most important reservoirs of plant diversity (Medail and Quezel 1999) and one of the most vulnerable areas of the planet to climate change (Thuiller et al. 2005; Cuttelod et al. 2009; Moreno and Oechel 2012), the trait-environment relationship is still poorly investigated (Chelli et al. 2019). Here temperature is expected to increase (Senatore et al. 2011) together with an increase in weather extremes in both the sense of heavy rainfall and summer heat waves, with a high incidence of drought (ISAC-CNR 2009). In this context, shedding light on the trait-environment relationship along temperature and water stress gradients can help to interpret vegetation response under changing climatic conditions (Scherrer et al. 2017).

In the Mediterranean biogeographic region, shrublands are one of the most important and widespread vegetation types (Naveh and Whittaker 1979; Cowling et al. 1996; Shoshany and Karnibad 2011). Such vegetation is dominated by evergreen shrubs usually with small and sclerophyllous leaves as part of their drought tolerance strategy (Mooney and Dunn 1970).

Of all plant traits, those of leaves are among the most important when it comes to water-use strategies (Wilson et al. 1999; Vendramini et al. 2002). Specific Leaf Area (SLA, the lightcapturing surface area per unit of dry biomass, Poorter et al. 2009), is generally recognized as one of the most significant trait to study water and nutrient availability impacts on plant growth (Wright et al. 2001; Reich et al. 2014; Wellstein et al. 2017). Leaf Area (LA) is another trait which has significant implications regarding the regulation of leaf temperature and water-use efficiency during photosynthesis (Ackerly et al. 2002). SLA and LA are two fundamental traits influencing community structure and functioning of Mediterranean ecosystems (Gross et al. 2013).

In community level studies based on average trait values for species, LA and SLA usually showed parallel changes, which suggests that these traits are linked in their functional strategy associated with water and/or nutrient availability (Ackerly et al. 2002 and references therein). Accordingly, global studies showed a decrease in LA and SLA along with decreasing water and/or nutrient availability (Poorter et al. 2009; Wright et al. 2017). However, comparative studies accounting for species trait variability suggested that LA and SLA may not be strictly related (e.g. Ackerly et al. 2002), thus highlighting the importance of approaches taking into account both leaf traits and their intraspecific variation along environmental gradients. 
107 Decreased plant growth rates are associated with lower SLA values (Wellstein et al. 2017 and 108 references therein), and are often found under conditions of water stress (Chapin 1991), as they can 109 improve water-use efficiency (Wright et al. 2001). LA shows a similar trend, with small leaves 110 reducing resistance in the boundary layers and allowing the plant to maintain lowered temperatures 111 and higher photosynthetic water-use efficiency when solar radiation is high and water availability is 112 low (Wright et al. 2001; Ackerly et al. 2002). In short, SLA and LA are good proxies of broad 113 resource-use strategies and are negatively correlated with many other hard and soft leaf traits (e.g., 114 leaf toughness, leaf longevity, leaf dry matter content, stomatal conductance; Wright et al. 2002; 115 Reich et al. 2003; Wright et al. 2004; Hoffmann et al. 2005).

116 Few papers deal with changes in leaf traits along environmental gradients of shrubs communities in 117 Mediterranean-type climates (e.g., Ackerly et al. 2002; Ackerly 2004; Anacker et al. 2011, 118 conducted in North American chaparral), confirming the above described patterns of SLA and LA. 119 Additional studies used leaf traits to explore assembly rules along aridity gradients in shrublands of 120 the Mediterranean basin (e.g., Gross et al. 2013; Le Bagousse-Pinguet et al. 2015).

121 Looking at a single trait allows the range and distribution of values to inform the relationship 122 between ecosystem function and community structure (Ackerly et al. 2002). In order to summarize 123 the functional composition of plant communities for a certain trait taking into account species 124 abundances, Garnier et al. (2004) proposed the so-called 'community-weighted mean trait values' 125 (CWMs).

126 Changes in community composition along climate and soil gradients are expected to be strongly 127 represented in leaf traits, due to their reflection of water-use strategies (Le Bagousse-Pinguet et al. 128 2017). Increased variability in these leaf traits is expected when conditions are favorable for plant 129 life, e.g., water and temperature stress are reduced; soils are more fertile (Ackerly et al. 2002; 130 Hoffmann et al. 2005; Cornwell and Ackerly 2009). In contrast, habitat filtering may occur in the 131 face of extreme aridity or a reduction in water availability, reducing the distribution of SLA and LA 132 values within the community, and suggesting that species with high stress tolerance do not 133 generally inhabit broad environmental ranges (Thuiller et al. 2004).

135 Most studies focusing on trait-environment relationships along gradients used only mean trait 136 values per species (usually weighted by species proportions), assuming that between-species trait 137 variation is generally considerably greater (e.g. Cornelissen et al. 2003) than within species 138 variation. However, it is clear that some traits are more variable than others (Siefert et al. 2015), and 139 a growing number of studies confirm that intraspecific variation could play a relevant role to shifts 140 in community-level trait measures (i.e., Lepš et al. 2011; Kichenin et al. 2013) and assembly rules 141 (i.e., Jung et al. 2010; Le Bagousse-Pinguet et al. 2015) along environmental gradients. In 
142 particular, both SLA (Wellstein et al. 2013, 2017; Liancourt et al. 2015) and LA (Fraser et al. 2009)

143 showed a certain intraspecific variation, with SLA demonstrating a larger one (Rozendaal et al. 144 2006; Siefert et al. 2015).

146 In this paper, we aimed to assess the patterns of community level leaf traits (namely, SLA and LA) along an elevation gradient $(1,300 \mathrm{~m})$ spanning four thermotypes or thermometric belts, defined on the basis of temperature data condensed in two indexes ( It $=$ thermometric index; $\mathrm{Tp}=$ positive annual temperature), following Rivas-Martìnez et al. (2011) method, and mapped by Canu et al. (2015) in Mediterranean shrubland ecosystems in the island of Sardinia (Italy). We measured leaf traits at plot level in order to take into account intraspecific variability. In particular, we propose the following hypotheses:

153 H1 SLA and LA at community-level should be significantly lower in the most arid climate 154 (thermotype 1) compared to the most cool and moist environment (thermotype 4).

155 H2 The variability of both leaf traits (in terms of variance) should increase (niche differentiation) toward the cooler and moister end of the gradient (thermotype 4). Furthermore, we disentangled the contribution of interspecific (i.e. species turnover) and intraspecific trait variation to shifts in CWM values along the gradient, hypothesizing (H3) a significant influence of intraspecific variation in both leaf traits.

\section{MATERIALS AND METHODS}

\section{Study area}

163 Sardinia, the second largest island in the Mediterranean Sea (ca. 24,090 $\mathrm{km}^{2}$ ), has a unique flora as 164 a result of the unique geological history that played an essential role in shaping plant diversity 165 (Medail and Quezel 1999; Mansion et al. 2008). The Sardinian flora consists of 2,301 native vascular plants (Bartolucci et al. 2018), of which more than 170 are endemic to the island: concentrated mainly in the mountains (Cañadas et al. 2014). This study has been conducted in the NE part of Sardinia (Figure 1), locally known as the Gallura subregion, with constant geology in the altitudinal gradient, being characterized by Hercynian granites, having homogeneous slopes and patterns of degradation. Furthermore, the selected area is also considered homogeneous from a biogeographic standpoint (Fenu et al. 2014). Altitude range in this area is from 0 (coast) to $1354 \mathrm{~m}$ (top of Mt. Limbara massif). This altitudinal gradient allows five different thermotypes to occur in the study area (Canu et al. 2015). Thermotypes are described on the basis of thermicity indexes

174 developed by the Worldwide Bioclimatic Classification System (Rivas-Martìnez et al. 2011). 175 Annual mean temperature ranged from $16.6^{\circ} \mathrm{C}$ in the coastal area to $10.5^{\circ} \mathrm{C}$ at the top of $\mathrm{Mt}$.

176 Limbara; annual rainfall ranged from $560 \mathrm{~mm}$ to $1160 \mathrm{~mm}$. 
177 Potential natural vegetation of the area (sensu Farris et al., 2010) is represented by different forest types depending on the thermotypes: the coastal thermo-Mediterranean belt is characterized by the presence of Phoenician juniper vegetation (Oleo-Juniperetum turbinatae and Erico-Juniperetum turbinatae on southern and northern slopes, respectively). Wild olive (Olea europaea) vegetation is prevalent in the lower meso-Mediterranean belt, holm-oak (Quercus ilex) vegetation prevails at both the upper meso-Mediterranean (Galio-Quercetum ilicis) and sub-Mediterranean and Temperate belts (Saniculo-Quercetum ilicis).

184 The intense past sylvo-pastoral management, that included the use of fire and extensive plantations of alien trees, changed the landscape and determined the current situation where the shrublands represent the most abundant plant communities present in the area.

\section{Sampling design}

To study a strong climatic gradient, we needed strata that could represent the range of temperatures and water stresses characterizing our study area, stretching from the coastline to the inner areas of Sardinia. To describe this gradient, we adopted a modified version of the thermotypes recognized in the bioclimatic map of Sardinia (Canu et al. 2015) where we unified the upper belts into a unique "temperate" cacuminal belt, to obtain 4 different thermotypes describing the whole transect (Figure 1): upper Thermomediterranean (T1); lower Mesomediterranean (T2); upper Mesomediterranean (T3) and lower Supratemperate (T4).

The study area was defined creating a grid of $1 \mathrm{~km}^{2}$ units including the Limbara massif and extending eastward toward the Olbia coastline (40 km gradient): regarding the other relevant environmental factors, we can consider geology (also soil), erosion patterns, history (including fire regime and cutting) and animal influence as constant along the bioclimatic gradient. From the original 495 quadrats, we excluded i) all the mixed quadrats crossing two thermotypes, and ii) all quadrats showing a land cover characterized by less than $50 \%$ of shrubs and garrigues (CLC Regione Sardegna). Among the remaining quadrats, within each of the four strata we selected five sampling quadrats; in each sampling quadrat, we performed a random selection of 2 sampling units $5 \times 5 \mathrm{~m}$. As a whole, we sampled 40 sample units of $25 \mathrm{~m}^{2}$ divided in 4 thermotypes ( 2 sample units x 5 quadrats $\times 4$ thermotypes) where we registered the complete species list and visually estimated the species coverage (\%) during May 2016 (Appendix 1). In each sampling unit, we selected all the species contributing to reach a relative cumulative coverage of $80 \%$. For each species, five leaves in full sun were sampled from five mature and healthy individuals; such sampling size adequately captures leaf traits intraspecific variability in Mediterranean contexts (Petruzzellis et al. 2017). In total, 900 individuals belonging to 33 species, including shrubs and herbs, were selected for leaf traits measurements (Appendix 1). We measured 
212 SLA and LA following standard protocols (Pérez-Harguindeguy et al. 2013): leaf area was 213 measured within few hours after collection; subsequently leaves were oven-dried for 72 hours at $21470^{\circ} \mathrm{C}$ and leaf dry mass was measured to calculate SLA. Community weighted mean values (CWM, 215 Garnier et al. 2004) were then calculated according to species plot-level cover values (i.e., we 216 averaged the species trait values from individual measurements taken in a given plot and used it to 217 calculate CWM of that plot). According to recent methodological studies (e.g. Peres-Neto et al. 218 2017; Zelený 2018), measuring traits for each species at each site, and using these plot-level trait measurements to calculate CWM, avoid the classic problem with inflated Type I error.

\section{Data analysis}

222 We analyzed the data to test the differences existing along the gradient, according to the following variables: i) Community composition - to observe differences in terms of species composition and abundance we performed a NMDS (standardized samples by total, Bray-Curtis resemblance). We integrated NMDS results with PERMANOVA (Anderson et al 2001; fixed factor: thermotypes, 9999 permutation, unrestricted permutation of raw data, Bray-Curtis resemblance)and a PERMDISP analyses, a test of the homogeneity of multivariate dispersions within groups, as PERMANOVA makes the implicit assumption that dispersions are roughly constant across groups; ii) Changes of CWM values - to test if CWM values of SLA and LA significantly changed according to the four thermotypes (H1), we used ANOVA for multiple samples and Bonferroni post-hoc test; iii) Trend in leaf traits variance - to test for changes in the variance of leaf traits along the gradient (H2), we used a trend test for monotonic trend in variance suggested by Neuhauser and Hothorn (2000). The test is based on the finite-intersection approach, the Brown-

234 Forsythe transformation, and Kendall's tau coefficient (Noguchi and Gel 2010; Gastwirth et al. 2015). The finite-intersection approach (Mudholkar et al. 1993) combines $p$ values of the component test statistics, which correspond to a finite number of nested hypotheses. Fisher's $p$ value combination method (Fisher 1934) is used in this study. Finally, to distinguish iv) the relative contribution of inter- and intraspecific variation on community-level trait values (H3) we followed the approach proposed by Lepš et al. (2011). This method is based on the decomposition of the total sum of squares $\left(\mathrm{SS}_{\text {specific }}\right)$ of the plot-level trait variance related to a certain environmental variable into "interspecific" (or "fixed") $\left(\mathrm{SS}_{\text {interspecific }}\right)$, "intraspecific" $\left(\mathrm{SS}_{\text {intraspecific }}\right)$ and "covariation" $\left(\mathrm{SS}_{\text {cov }}\right)$ components, so that $\mathrm{SS}_{\text {specific }}=\mathrm{SS}_{\text {interspecific }}+\mathrm{SS}_{\text {intraspecific }}+\mathrm{SS}_{\text {cov }}$ (Kichenin et al.

243 2013). Firstly, for each plot, we calculated "specific" plot-average trait values using species trait

244 values as measured on that plot (which includes both inter- and intraspecific components), and "interspecific" (or "fixed") plot-average trait values using species trait values averaged over all plots along the selected environmental gradient (which takes into account only species turnover and 
removes the intraspecific variability component). Secondly, we calculated "intraspecific" plot averages as the difference between "specific" and "interspecific" plot-average trait values (thus removing the component of interspecific variability). Thirdly, the "covariation" component (i.e., the effect of covariation between interspecific and intraspecific trait variation) was obtained as follows: $\mathrm{SS}_{\text {cov }}=\mathrm{SS}_{\text {specific }}-\mathrm{SS}_{\text {interspecific }}-\mathrm{SS}_{\text {intraspecific }}$. As environmental variables we used both categorial (i.e., thermotype) and continuous ones (i.e., temperature seasonality and Potential EvapoTranspiration, PET; Canu et al. 2015).

All statistical analyses were performed in R, version 3.2.2 ( $\mathrm{R}$ Development Core Team 2015). In particular the following $\mathrm{R}$ packages were used: package vegan (function betadisper) for the analysis of multivariate homogeneity of group dispersion; package lawstat (function neuhauser.hothorn.test) for the trend test for monotonic trend in variance (Neuhauser and Hothorn 2000); Package cati (function traitflex.anova) for the analysis on the relative contribution of inter- and intraspecific variation on community weighted mean values (Lepš et al. 2011).

\section{RESULTS}

\section{Community composition and species assemblages}

264 We found shrub communities, physiognomically referred to as Euphorbio dendroidisCalicotometum villosae prevalent at the upper Thermomediterranean belt (T1), Pistacio lentisciCalicotometum villosae dominant at the lower Mesomediterranean (T2), Erico-Arbutetum widespread at the upper Mesomediterranean (T3) and Ericetum scopario-arboreae dominating at sub-Mediterranean and Temperate belts (T4, Farris et al. 2007; Galié et al. 2015). Plant communities differ between thermotypes (PERMANOVA $\mathrm{p}<0.05$ for all pairwise tests; PERMDISP $\mathrm{p}>0.05$ ). The sub-Mediterranean and Temperate Ericetum scopario-arboreae (belt T4) is the community that mostly diverged from the others (NMDS, figure 2), on the contrary Euphorbio dendroidis-Calicotometum villosae of the Thermomediterranean belt (T1) is the community that,

273 being statistically different from the others, appeared less distinct from Pistacio lentisci-

Calicotometum villosae and Erico-Arbutetum(T2 and T3)

\section{Community-level traits variation}

Significant differences between community-level SLA values have been found $(p<0.05)$. In detail, $\mathrm{T} 1\left(\mathrm{SLA}=8.83 \mathrm{~mm}^{2 *} \mathrm{mg}^{-1}\right)$ and $\mathrm{T} 4\left(\mathrm{SLA}=13.51 \mathrm{~mm}^{2} * \mathrm{mg}^{-1}\right)$ were significantly different according to Bonferroni post-hoc test $(\mathrm{p}<0.05$; Figure $3 \mathrm{a})$. Furthermore, we observed a significant increase in variability along the gradient from $\mathrm{T} 1$ to $\mathrm{T} 4$ (Test Statistic $=3.115 ; \mathrm{p}<0.01$ ). Regarding LA, ANOVA showed significant differences between thermotypes $(\mathrm{p}<0.05)$. Differences were found between $\mathrm{T} 2$ 
$282\left(\mathrm{LA}=410.04 \mathrm{~mm}^{2}\right), \mathrm{T} 3\left(\mathrm{LA}=407,87 \mathrm{~mm}^{2}\right)$ and T4 $\left(\mathrm{LA}=102,33 \mathrm{~mm}^{2} ; \mathrm{p}<0.05\right.$; Figure $\left.3 \mathrm{~b}\right)$, with the

283 lowest mean values found at T4. No significant trends in LA variability were detected along the 284 gradient.

\section{Contribution of inter- and intraspecific variation}

The contributions of inter- and intraspecific variability in explaining the response of communitylevel SLA and LA variation to the three environmental variables (i.e., thermotype, temperature seasonality, PET) were both significant only for "thermotypes" ( $p<0.01$; Figure 4$)$. On the contrary, along the temperature seasonality gradient the contribution of species turnover was significant only for SLA $(p<0.05)$, while along the PET gradient both the components were not significant for both leaf traits. For SLA, the total variability effects were significant for all the three variables $(\mathrm{p}<0.05)$ and was highest for the variable "thermotype" (19.61\%). Here species turnover and intraspecific variability showed a similar contribution (turnover $=42.05 \%$; intraspecific $=36.04 \%$ ), but there was a strong negative covariation $(-58.48 \%)$ between the effects of inter- and intraspecific variability on CWM values of SLA. For LA the total variability effects were significant only for "thermotype" $(26.36 \%$; $<0.01)$. Here species turnover showed a higher contribution $(23.88 \%)$ with respect to intraspecific variability (12.25\%), with a negative covariation $(-9.77 \%)$.

\section{DISCUSSION}

Our study explored the leaf trait-environment relationship along an elevation gradient across four thermotypes in Mediterranean shrubland ecosystems. The large environmental gradient included four types of compositionally different plant communities. SLA and LA showed different patterns in both abundance-weighted values and variability along the gradient. Additionally, the studied leaf traits differed in the relative contribution of species turnover and intraspecific variation to their changes at community level along the gradient, with SLA showing a relevant contribution of intraspecific variation, higher with respect to LA. Overall, our results highlight the importance of approaches considering simultaneously different traits and their intraspecific variability, even in studies encompassing steep environmental gradients (Lepš et al. 2011; Kichenin et al. 2013; Derroire et al. 2018; Garnier et al. 2018).

\section{Changes in CWM values and variability}

313 Our results showed significantly different values of community-level SLA between the two

314 extremes of the gradient, with lower values in the driest thermotype. On the contrary, community315 level LA values were significantly different only between T2-3 and T4, leading us to confirm H1 of 316 lower leaf traits values in the most arid thermotype only for SLA. Regarding trait variability, our 
317 hypothesis (H2) of increasing variability of both leaf traits toward the cooler and moister end of the 318 gradient (T4) is confirmed only for SLA, while LA showed the lowest level of variability in the cooler and moister extreme of the gradient. Variation in the patterns of SLA and LA in the present study accross the climatic gradient confirm the expectation that the two leaf traits are not strictly correlated if species variability is properly accounted. The advantage of looking at variation within a trait (instead of using average and fixed trait values) allows us to seperate the behaviour of the two traits (as in Ackerly et al. 2002). The lowest community level SLA values were found in the driest thermotype, which reflects the increase in water use efficiency in a more arid environment (Wright et al. 2001; Wellstein et al. 2017). Low SLA values and decreased plant growth rates usually reflect water stress (Chapin 1991). Moreover, T1 is characterized by the lowest SLA variability, most likely indicating a strong habitat filtering generating a convergence in leaf strategy to cope with drought in our system (see also Wright et al. 2002). Under drought conditions, leaves tend to have a denser mesophyll layer, and cells with thicker cell walls, this helps avoid wilt (Shield 1950; Poorter et al. 2009; Wellstein et al. 2017). The increase in SLA variability along the gradient can be explained by the occurrence of more benign conditions, thus allowing the coexistance of species/individuals with different functional strategies related to water-use based on different mechanisms of coexistence (see Wellstein et al. 2014).

Low LA generally leads to high water stress tolerances, whereas species equipped with large leaves are better suited to mesic environments (Westoby et al. 2002). Accordingly, we would expect larger and more variable LA due to more benign conditions in terms of temperature and water availability in T4. However, our results indicated that different habitat filtering mechanisms are acting on this trait leading to both low values of abundance-weighted mean and variability in the two extremes of the gradient. Our findings are consistent with those of Gross et al. (2013), who found a quadratic relationship between functional diversity and mean LA values along a rainfall gradient in

342 Mediterranean shrublands. We propose different explanations for the unexpected strong 343 convergence to low mean LA values in T4. Firstly, LA is a key trait that is strongly influenced by 344 air temperature (Wright et al. 2017). Noctural low temperatures in particular seem to have the most 345 significant impact on LA (Wright et al. 2017 and references therein). The T4 is in fact the only 346 thermothype having average lower temperatures in the coldest month approaching $0^{\circ} \mathrm{C}\left(0.4^{\circ} \mathrm{C}\right.$ in the locality Vallicciola at $1040 \mathrm{~m}$ a.s.l. on Limbara massif), and an average snow cover of 3-4 weeks every year (Farris et al. 2007). Secondly, functional trade-offs between different plant traits could be significant in combined trait responses to increase the variety of ways that plants can respond to environmental stress (Givnish 1984; Marks and Lechowicz 2006; West et al. 2012). Thirdly, LA is more strongly anchored to species identity than SLA, and thus more responsive to species turnover. 
352 These results correspond to the ones of Kichenin et al. (2013) who found a major contribution of 353 interspecific variability in explaining the response of LA to elevation. Since T4 is characterized by 354 plant communities that mostly diverged from the others in terms of species composition, here the 355 compositional changes were reflected by dramatic changes in functional strategy in terms of LA. Accordingly, plant communities of T4 were dominated by Erica arborea and Erica scoparia, both characterized by small persistent linear leaves. On the contrary, for SLA the species compositional changes between T2-3 and T4 were not reflected by a functional shift. In other words, the different plastic behaviour of these two leaf traits could be behind the unexpected pattern of LA in T4 outlining the relevance of intraspecific variation. In contrast to the majority of many other leaf traits, SLA is related to the cell volume ratio of leaf parenchyma to epidermis cells, making it more plastic than traits dependent on subcellular processes (Kichenin et al. 2013). Mitchell and Bakker (2014) found SLA variation to be mostly based on plasticity with low relevance of ontogeny or local adaptation. For size dependency of SLA and further discussion see Milla et al. (2008).

\section{The relative contribution of intraspecific variation}

Our finding of a similar relative contribution of inter- and intraspecific community-level SLA variation (55\% and $45 \%$, respectively) along the gradient of four thermotypes, confirms the plasticity of this trait (Liancourt et al. 2015; Siefert et al. 2015; Wellstein et al. 2017). Kichenin et al. (2013) found similar patterns along a $900 \mathrm{~m}$ elevation gradient spanning subalpine and alpine plant communities in New Zealand. However, the effect of species turnover can be more marked along other environmental gradients (here, e.g. with temperature seasonality), as also showed by Lepš et al. (2011). Regarding LA, the relative contribution of species turnover is twice as big as intraspecific variation (66.1\% and $33.9 \%$, respectively) along the gradient of four thermotypes. Despite the plastic behaviour that this trait has shown (Fraser et al. 2009), we demonstrated that its changes at the community level were mostly dependent on species turnover (Rozendaal et al. 2006; Siefert et al. 2015). These results lead us to confirm H3 on a significant influence of intraspecific variation in both leaf traits, but with a larger role of this component for SLA. It is most likely that SLA varies with high temperature and low water availability at the intraspecific level (Ackerly 2004; Poorter et al. 2009; Wellstein et al. 2017) which are known to strongly decrease with increasing elevation in Mediterranean contexts.

Moreover, our results provide relevant implications for future studies focusing on leaf traitenvironment relationship in Mediterranean contexts. Indeed, the measurements of individual traits within species show that trait-based community responses to environmental changes are not adequately predicted using leaf traits mean values (Lepš et al. 2011). This is in part due to the influence of intraspecific trait variation (Garnier et al. 2018; Kickenin et al. 2013). In particular, the 
significantly negative covariation between inter- and intraspecific SLA variation suggests that there is a negative compensation between them. For example, in species with high SLA, individuals with lower SLA values may be promoted, and in species of lower SLA, individuals with higher values are promoted. This topic is worthy of further research, as significant uncertainty remains about the complex responses of plant communities to the environment (Lepš et al. 2011).

\section{Acknowledgements}

394 We thank Horiyet Abliz, Silvia Masci and Chiara Chelo for assistance during the field sampling.

\section{Electronic supplementary material}

Appendix 1. Species x plot matrix.

\section{Conflict of interest}

400 The authors declare that they have no conflict of interest.

\section{REFERENCES}

Ackerly DD, Knight CA, Weiss SB, Barton K, Starmer KP (2002) Leaf size, specific leaf area and microhabitat distribution of chaparral woody plants: contrasting patterns in species level and community level analyses. Oecologia 130:449-457

Ackerly DD (2004) Functional traits of chaparral shrubs in relation to seasonal water deficit and disturbance. Ecol Mon 74:25-44

Anacker B, Rajakaruna N, Ackerly D, Harrison H, Keeley J, Vasey M (2011) Ecological strategies in California chaparral: interacting effects of soils, climate, and fire on specific leaf area. Plant Ecol Divers 4:179-188

Anderson MJ (2001) Permutation tests for univariate or multivariate analysis of variance and regression. Can J Fish Aquatic Sci 58:626-639

Bartolucci F, Peruzzi L, Galasso G, Albano A, Alessandrini A, Ardenghi NMG, et al (2018) An updated checklist of the vascular flora native to Italy. Plant Biosyst 152:179-303

Cañadas EM, Fenu G, Penas J, Lorite J, Mattana E, Bacchetta G (2014) Hotspots within hotspots: Endemic plant richness, environmental drivers, and implications for conservation. Biol Conserv 170:282-291

Canu S, Rosati L, Fiori M, Motroni A, Filigheddu R, Farris E (2015) Bioclimate map of Sardinia (Italy). J Maps 11:711-718

Chapin FS (1991) Integrated responses of plants to stress. BioScience 41:29-36

Chelli S, Marignani M, Barni E, et al (2019) Plant-environment interactions through a functional 
traits perspective: a review of italian studies. Plant Biosyst https://doi.org/10.1080/11263504.2018.1559250

Cornwell WK, Ackerly DD (2009) Community assembly and shifts in plant trait distributions across an environmental gradient in coastal California. Ecol Mon 79:109-126

Cornelissen JHC, Lavorel S, Garnier E, Diaz S, Buchmann N, Gurvich DE, et al (2003) A handbook of protocols for standardised and easy measurement of plant functional traits worldwide. Aust J Bot 51:335-380

Cowling RM, Rundel PW, Lamont BB, Arroyo MK, Arianoutsou M (1996) Plant diversity in Mediterranean climate regions. Trends Ecol Evol 11:362-366

Cuttelod A, García N, Malak DA, Temple HJ, Katariya V (2009) The Mediterranean: a biodiversity hotspot under threat. Wildlife in a Changing World-an analysis of the 2008 IUCN Red List of Threatened Species, 89.

Derroire G, Powers JS, Hulshof CM, Varela LEC, Healey JR (2018) Contrasting patterns of leaf trait variation among and within species during tropical dry forest succession in Costa Rica. Sci Rep 8:285

Farris E, Secchi Z, Filigheddu R (2007) Phytosociological study of the shrub and pre-forest communities of the effusive substrata of NW Sardinia. Fitosociologia 44:55-81

Farris E, Filibeck G, Marignani M, Rosati L (2010) The power of potential natural vegetation (and of spatial-temporal scale): A response to Carrión \& Fernández (2009). J Biogeogr 37:2211-2213

Fenu G, Fois M, Cañadas EM, Bacchetta G (2014) Using endemic-plant distribution, geology and geomorphology in biogeography: the case of Sardinia (Mediterranean Basin). Syst Biodivers $12: 181-193$

Fisher RA (1934) Statistical Methods for Research Workers. 5th edn. Edinburgh: Oliver and Boyd.

Fraser LH, Greenall A, Carlyle C, Turkington R, Friedman CR (2009) Adaptive phenotypic plasticity of Pseudoroegneria spicata: response of stomatal density, leaf area and biomass to changes in water supply and increased temperature. Ann Bot-London 103:769-775

Galié M, Gasparri R, Perta RM, Biondi E, Biscotti N, Pesaresi S, Casavecchi S (2015) Post-fire regeneration of Calicotome villosa (Poiret) Link and vegetation analysis. Plant Sociology 52(2): $101-120$

Garnier E, Cortez J, Billès G, Navas ML, Roumet C, Debussche M, et al (2004) Plant functional markers capture ecosystem properties during secondary succession. Ecol 85:2630-2637

Garnier E, Navas ML, Grigulis K (2016) Plant functional diversity: Organism traits, community structure, and ecosystem properties. Oxford University Press

Garnier E, Vile D, Roumet C, Lavorel S, Grigulis K, Navas ML, Lloret F (2018) Inter- and intraspecific trait shifts among sites differing in drought conditions at the north western edge of the 
Gastwirth JL, Gel YR, Wallace Hui WL, Lyubchich V, Miao W, Noguchi K (2015) Package 'lawstat'. Available at: https://cran.r-project.org/web/packages/lawstat/lawstat.pdf

Givnish TJ (1984) Leaf and canopy adaptations in tropical forests. In Physiological ecology of plants of the wet tropics (pp. 51-84). Springer, Dordrecht

Gross N, Börger L, Soriano- Morales SI, Le Bagousse- Pinguet Y, Quero JL, García- Gómez M, et al (2013) Uncovering multiscale effects of aridity and biotic interactions on the functional structure of Mediterranean shrublands. J Ecol 101:637-649

Hoffmann WA, Franco AC, Moreira MZ, Haridasan M (2005) Specific leaf area explains differences in leaf traits between congeneric savanna and forest trees. Funct Ecol 19:932-940

ISAC-CNR (2009) Clima, cambiamenti climatici globali e loro impatto sul territorio nazionale. Quaderni dell'ISAC, Vol 1. ISAC-CNR, Bologna

Jung V, Violle C, Mondy C, Hoffmann L, Muller S (2010) Intraspecific variability and trait-based community assembly. J Ecol 98:1134-1140

Kichenin E, Wardle DA, Peltzer DA, Morse CW, Freschet GT (2013) Contrasting effects of plant inter- and intraspecific variation on community-level trait measures along an environmental gradient. Funct Ecol 27:1254-1261

Le Bagousse- Pinguet Y, Börger L, Quero JL, García- Gómez M, Soriano S, Maestre FT, Gross N (2015) Traits of neighbouring plants and space limitation determine intraspecific trait variability in semi- arid shrublands. J Ecol 103:1647-1657

Le Bagousse- Pinguet Y, Gross N, Maestre FT, Maire V, De Bello F, Fonseca CR, Kattge J, Valencia E, Leps J, Liancourt P (2017) Testing the environmental filtering concept in global drylands. J Ecol 105:1058-1069

Lepš J, de Bello F, Šmilauer P, Doležal J (2011) Community trait response to environment: disentangling species turnover vs intraspecific trait variability effects. Ecography 34:856-863

Liancourt P, Boldgiv B, Song DS, Spence LA, Helliker BR, Petraitis PS, Casper BB (2015) Leaftrait plasticity and species vulnerability to climate change in a Mongolian steppe. Glob Change Biol 21:3489-3498

Mansion G, Rosenbaum G, Schoenenberger J, Bacchetta G, Rossell OJ, Conti E (2008) Phylogenetic analysis informed by geological history supports multiple, sequential invasions of the Mediterranean basin by the Angiosperm family Araceae. Syst Biol 57:269-285

Marks CO, Lechowicz MJ (2006) Alternative designs and the evolution of functional diversity. Am Nat 167:55-67

Medail F, Quezel P (1999) Biodiversity hotspots in the Mediterranean Basin: setting global conservation priorities. Conserv Biol 13:1510-1513 
492 Milla R, Rich PB, Niinemets Ü, Castro-Díez P (2008) Environmental and developmental controls 493 on specific leaf area are little modified by leaf allometry. Funct Ecol 22:565-576

494 Mitchell RM, Bakker JD (2014) Intraspecific Trait Variation Driven by Plasticity and Ontogeny in Hypochaeris radicata. PLoS ONE 9(10):e109870

Mooney HA, Dunn EL (1970) Convergent evolution of Mediterranean-climate evergreen sclerophyllous shrubs. Evolution 24:292-303

Moreno J, Oechel WC (Eds.) (2012) Global change and Mediterranean-type ecosystems (Vol. 117). Springer Science \& Business Media

Mudholkar GS, McDermott MP, Aumont J (1993) 'Testing homogeneity of ordered variances', Metrika 40:271-281

Naveh Z, Whittaker RH (1979) Structural and floristic diversity of shrublands and woodlands in northern Israel and other Mediterranean areas. Vegetatio 4:171-190

Neuhauser M, Hothorn LA (2000) Location-scale and scale trend tests based on Levene's transformation. Comput Stat Data An 33:189-200

Noguchi K and Gel YR (2010) Combination of Levene-type tests and a finiteintersection method for testing equality of variances against ordered alternatives. J Nonparametr Stat 22:897-913

Ordonez JC, van Bodegom PM, Witte JPM, Wright IJ, Reich PB, Aerts R (2009) A global study of relationships between leaf traits, climate and soil measures of nutrient fertility. Glob Ecol Biogeogr 18:137-149

Peres-Neto PR, Dray S, ter Braak CJF (2017) Linking trait variation to the environment: Critical issues with community-weighted mean correlation resolved by the fourth-corner approach. Ecography 40:806-816

Pérez-Harguindeguy N, Díaz S, Garnier E, et al (2013) New handbook for standardised

Reich PB, Wright IJ, Cavender-Bares J, Craine JM, Oleksyn J, Westoby M, Walters MB (2003) measurement of plant functional traits worldwide. Au J Bot 61:167-234.

Petruzzellis F, Palandrani C, Savi T, Alberti R, Nardini A, Bacaro G (2017) Sampling intraspecific variability in leaf functional traits: Practical suggestions to maximize collected information. Ecol Evol 7 (24): 11236-11245 DOI: 10.1002/ece3.3617

Poorter H, Niinemets U, Poorter L, Wright IJ, Villar R (2009) Causes and consequences of variation in leaf mass per area (LMA): A meta-analysis. New Phytol 182:565-588

R Core Team (2015) R: A language and environment for statistical computing. R Foundation for The evolution of plant functional variation: traits, spectra, and strategies. Int J Plant Sci 164:143164

Reich PB (2014) The world- wide 'fast-slow'plant economics spectrum: a traits manifesto. J Ecol 
102:275-301

Rivas-Martìnez S, Rivas-Sàenz S, Penas-Merino (2011) Worldwide Bioclimatic classification system. Glob Geobot 1:1-638

Rozendaal DMA, Hurtado VH, Poorter L (2006) Plasticity in leaf traits of 38 tropical tree species in response to light; relationships with light demand and adult stature. Funct Ecol 20:207-216

Scherrer D, Massy S, Meier S, Vittoz P, Guisan A (2017) Assessing and predicting shifts in mountain forest composition across 25 years of climate change. Divers Distrib 23:517-528

Senatore A, Mendicino G, Smiatek G, Kunstmann H (2011) Regional climate change projections and hydrological impact analysis for a Mediterranean basin in Southern Italy. J Hydrol 399:70-92

Shield LM (1950) Leaf xeromorphy as related to physiological and structural influences. Botanical Review 16:399-447

Shipley B, De Bello F, Cornelissen JHC, Laliberté E, Laughlin DC, Reich PB (2016) Reinforcing loose foundation stones in trait-based plant ecology. Oecologia 180:923-931

Shoshany M, Karnibad L (2011) Mapping shrubland biomass along Mediterranean climatic gradients: The synergy of rainfall-based and NDVI-based models. Int J Rem Sens 32:9497-9508

Siefert A, Violle C, Chalmandrier L, Albert CH, Taudiere A, Fajardo A, et al (2015) A global metaanalysis of the relative extent of intraspecific trait variation in plant communities. Ecol Lett $18: 1406-1419$

Thuiller W, Lavorel S, Midgley G, Lavergne S, Rebelo T (2004) Relating plant traits and species distributions along bioclimatic gradients for 88 leucadendron taxa. Ecology 85:1688-1699

Thuiller W, Lavorel S, Araújo MB, Sykes MT, Prentice IC (2005) Climate change threats to plant diversity in Europe. PNAS 102:8245-8250

Vendramini F, Díaz S, Gurvich DE, Wilson PJ, Thompson K, Hodgson JG (2002) Leaf traits as indicators of resource- use strategy in floras with succulent species. New Phytol 154:147-157.

Wellstein C, Poschlod P, Gohlke A, Chelli S, Campetella G, Rosbakh S, Canullo R, Kreyling J, Jentsch A, Beierkuhnlein C (2017) Effects of extreme drought on specific leaf area of grassland species: a meta-analysis of experimental studies in temperate and sub-Mediterranean systems. Glob Change Biol 23:2473-2481

Wellstein C, Campetella G, Spada F, Chelli S, Mucina L, Canullo R, Bartha S (2014) Contextdependent assembly rules and the role of dominating grasses in semi-natural abandoned subMediterranean grasslands. Agr Ecosyst Environ 182:113-122

Wellstein C, Chelli S, Campetella G, Bartha S, Galiè M, Spada F, Canullo R (2013) Intraspecific phenotypic variability of plant functional traits in contrasting mountain grassland habitats. 
Biodiv Conserv 22:2353-2374

563 West AG, Dawson TE, February EC, Midgley GF, Bond WJ, Aston TL (2012) Diverse functional responses to drought in a Mediterranean- type shrubland in South Africa. New Phytol 195:396-

566 Westoby M, Falster DS, Moles AT, Vesk PA, Wright IJ (2002) Plant ecological strategies: some leading dimensions of variation between species. Annu Rev Ecol Syst 33:125-159

568 Wilson PJ, Thompson KEN, Hodgson JG (1999) Specific leaf area and leaf dry matter content as 569 alternative predictors of plant strategies. New Phytol 143:155-162

570 Wright IJ, Reich PB, Westoby M (2001) Strategy shifts in leaf physiology, structure and nutrient 571 content between species of highand low-rainfall and high- and low-nutrient habitats. Funct Ecol

573 Wright IJ, Westoby M, Reich PB (2002) Convergence towards higher leaf mass per area in dry and 574 nutrient poor habitats has different consequences for leaf life span. J Ecol 90:534-543

575 Wright IJ, Reich PB,Westoby M, Ackerly DD, Baruch Z, Bongers F, Cavender-Bares J, Chapin T, 576 Cornelissen JHC, Diemer M (2004) The worldwide leaf economics spectrum. Nature 428:821$577 \quad 827$

578 Wright IJ, Dong N, Maire V, Prentice IC, Westoby M, Díaz S, et al (2017) Global climatic drivers 579 of leaf size. Science 357:917-921

Zelený D (2018) Which results of the standard test for community- weighted mean approach are too optimistic? J Veg Sci DOI: 10.1111/jvs.12688 


\section{FIGURES}

583 Figure 1. Study area and scheme of the sampling design. T1-T4 gradient is represented by white to dark grey areas. The selected sampling quadrats are highlighted in black; each quadrat includes two sampling units 5 x $5 \mathrm{~m}$.

\section{Legend}

Thermotypes

$\square$ Lower Supra-Temperate $\square$ Upper Meso-Mediterranean $\square$ Lower Meso-Mediterranean $\square$ Upper Thermo-Mediterranean
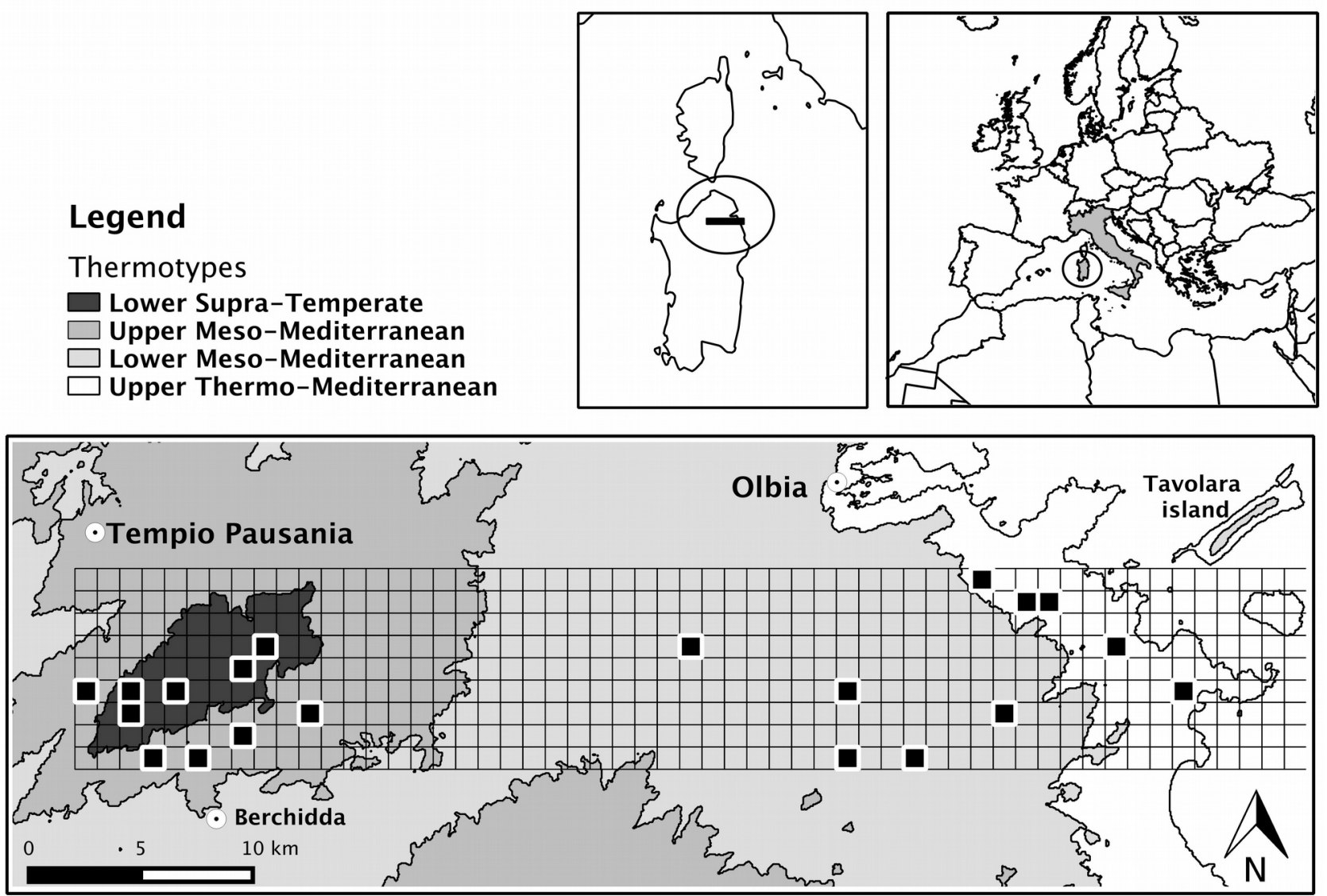
600 Figure 2. Non-metric multidimensional scaling (NMDS) plot of a 2-dimensional solution (Bray601 Curtis similarities, standardized samples by total, abundance data - stress 0.13). We represented the 602 species showing a higher correlation to the ordination axes (Spearman rho $>0,6)$. Species are 603 labelled as follows: Ave_bar: Avena barbata; Orn_com: Ornithopus compressus; Asp_alb: 604 Asparagus albus; Tri_cam: Trifolium campestre; Cis_mon: Cistus monspeliensis; Bri_max: Briza 605 maxima; Gal_ele: Galactites elegans; Vic_vil: Vicia villosa; Cis_sal: Cistus salviifolius; Que_ile: 606 Quercus ilex; Eri_arb: Erica arborea; Bra_ret: Brachypodium retusum; Rub_ulm: Rubus ulmifolius; 607 Car_car: Carex caryophyllea; Vio_riv: Viola riviniana; Cra_mon: Crataegus monogyna; Eri_sco: 608 Erica scoparia.

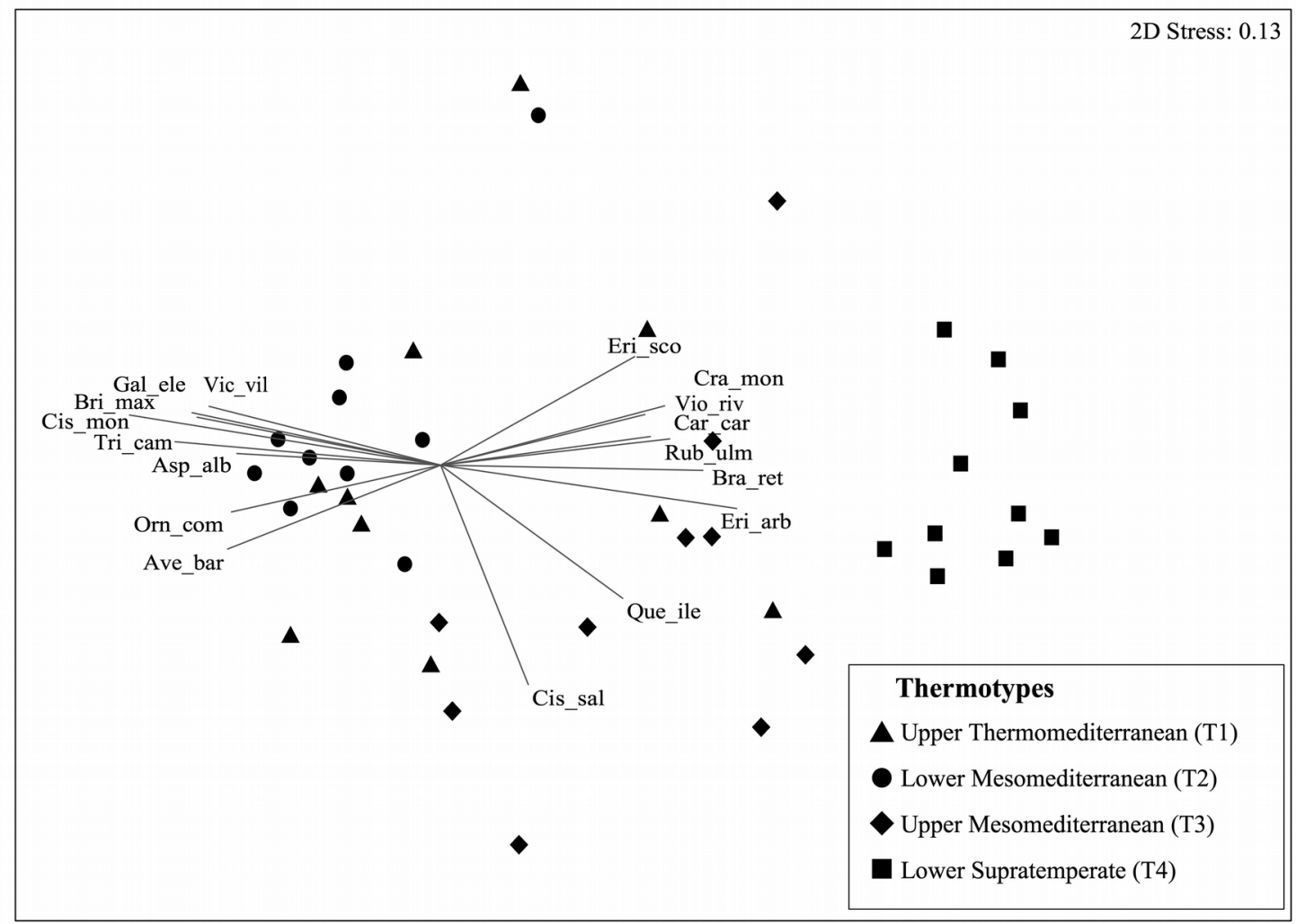


622 Figure 3. Boxplots of community-level SLA (a) and LA (b) for each thermotype (increasing 623 elevation and decreasing heat and water stress from T1 to T4). Significant differences between 624 mean values are indicated by different letters according to ANOVA $(p<0.05)$.

625 a)

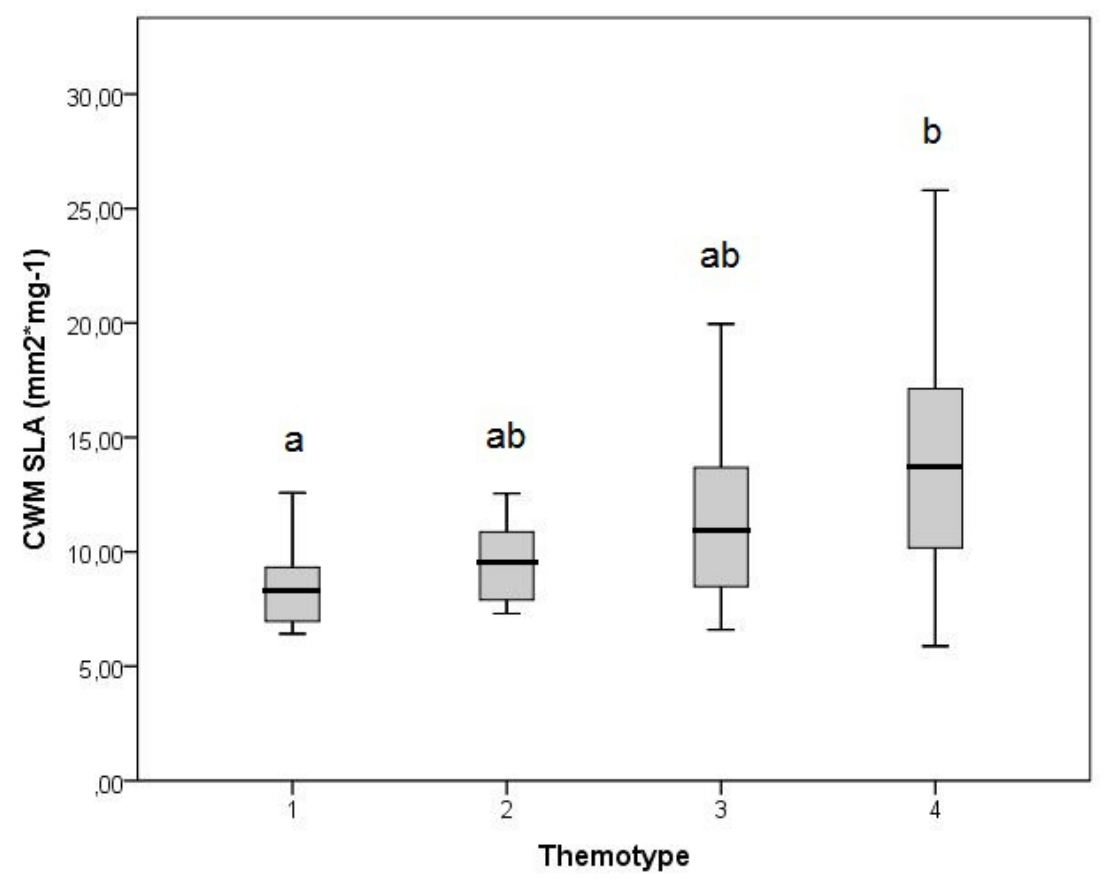

626

627 b)

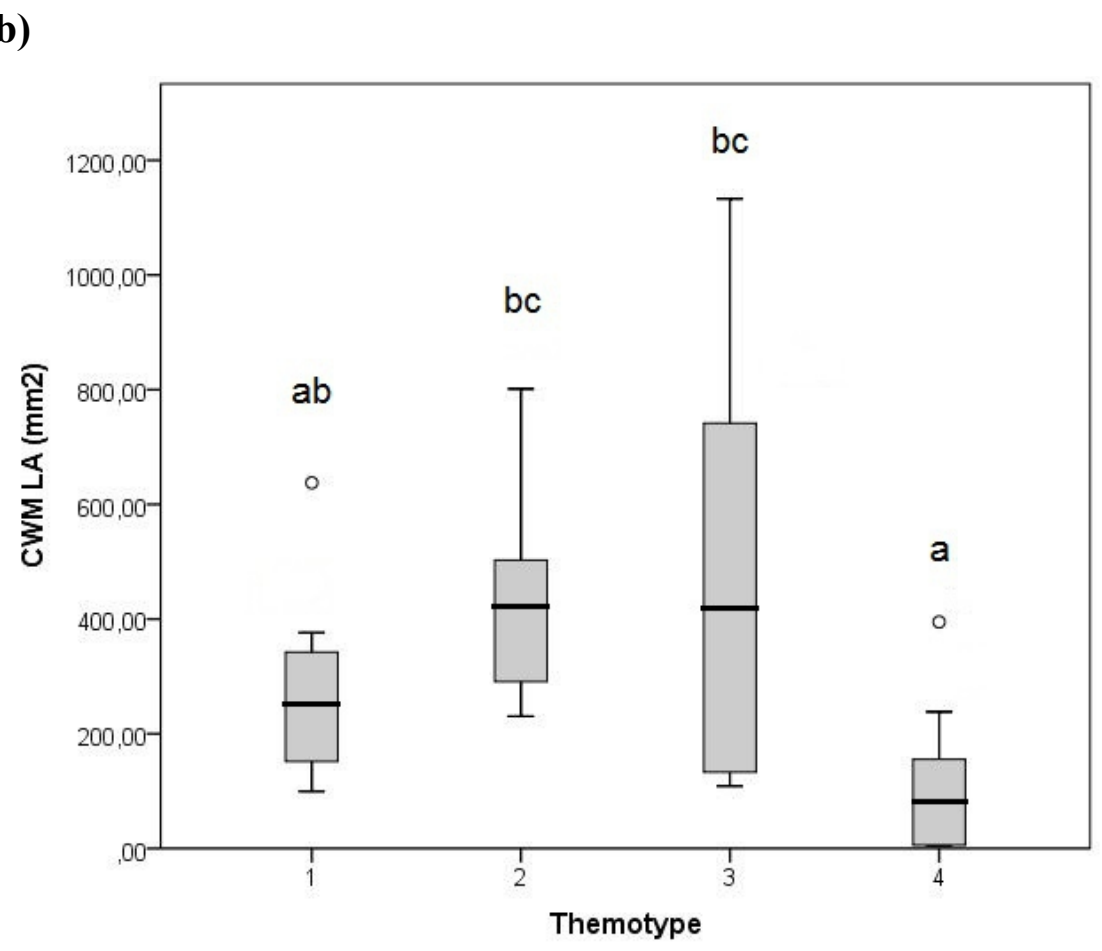

628

629 
630 Figure 4. Decomposition of total variability in community weighted mean SLA (a) and LA (b)

631 values into interspecific (species turnover), intraspecific and covariation effect explained by

632 temperature seasonality, PET and thermotypes. Covariation strength is represented by the interval

633 between the "total variability" and the sum of inter- and intraspecific variability effects. A value of

634 total variability that is lower than the sum of inter- and intraspecific variability effects indicates

635 negative covariations, and a value of total variability that is higher than the sum of inter- and

636 intraspecific variability effects indicates positive covariations. Statistical significance (*) of inter-,

637 intraspecific and total variability effects are indicated on the graph, when significant.

638

a)

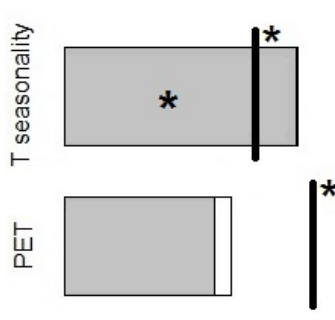

Interspecific variability effect (species turnover)

Intraspecific variability effect

Total variability: inter + intra + covariance

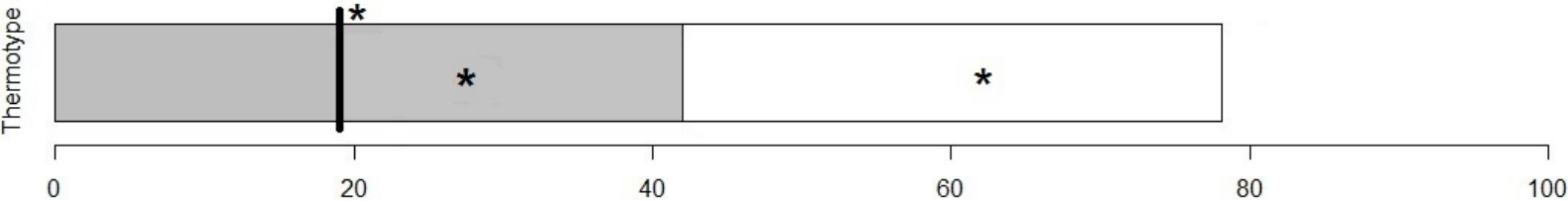

b)

$\%$ explained variability

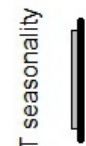

㟧 $\square$
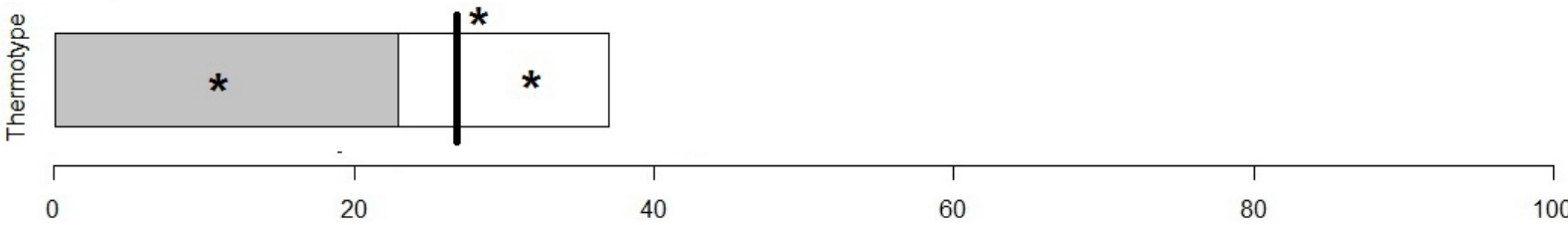

639

$\%$ explained variability 